\title{
A CONSTITUIÇÃ̃ HERMENÊUTICA FILOSÓFICA DAS CIÊNCIAS HUMANAS EM HANS-GEORG GADAMER
}

\author{
Paulo Thiago Alves Sousa ${ }^{1}$ \\ Universidade Federal do Piauí (UFPI) \\ Universidade Estadual do Piauí (UESPI) \\ iD https://orcid.org/0000-0001-8204-1890 \\ E-mail:pthiago21@hotmail.com
}

\section{RESUMO:}

O presente artigo tem como objetivo analisar, a partir da obra Verdade e Método, as principais perspectivas que dão fundamentação para a tese gadameriana de uma hermenêutica filosófica inerentes as ciências humanas. A hipótese principal é que Gadamer desenvolve uma reflexão não-metodológica para as ciências humanas guiada pela relação inextricável entre hermenêutica crítica e a linguagem, entendida como o modo de ser dialógico da interpretação. Para desenvolver tal hipótese, três momentos são relevantes: primeiro momento apresenta o caminho nãometodológico de Gadamer a partir da apropriação dos conceitos de tato, do jogo e da arte. No segundo momento, avança sobre o amadurecimento gadameriano da hermenêutica das ciências humanas a partir da noção de hermenêutica da faticidade desenvolvida por Heidegger. No terceiro momento, constitui a aproximação entre hermenêutica e linguagem como ponto de diálogo com a tradição, fazendo-se, assim, aflorar a consciência história efeitual. Conclui-se que a constituição da hermenêutica das ciências humanas tem por objetivo principal preparar para uma consciência hermenêutica.

PALAVRAS-CHAVE: Hermenêutica; Ciências Humanas; Compreensão; Linguagem.

\section{THE PHILOSOPHICAL HERMENEUTIC CONSTITUTION OF HUMAN SCIENCES IN HANS-GEORG GADAMER}

\begin{abstract}
:
This article aims to analyze, from the work Truth and Method, as main perspectives that can support a hermeneutic philosophical device inherent as human sciences. The main hypothesis is that Gadamer develops a nonmethodological reflection for human sciences guided by the inextricable relationship between critical hermeneutics and language, understood as the dialogic way of interpreting interpretation. To develop such a hypothesis, three moments are relevant: the first moment presents Gadamer's non-methodological path from the appropriation of the concepts of touch, game and art. In the second moment, the security or maturation of hermeneutic devices in the human sciences, based on the notion of hermeneutics of fatality developed by Heidegger. In the third moment, use the approximation between hermeneutics and language as a point of dialogue with tradition, thus bringing it to the fore of the historic and effective conscience. It was concluded that the hermeneutic constitution of the human sciences has as main objective to prepare a hermeneutic conscience.
\end{abstract}

KEYWORD: Hermeneutics; Human Sciences; Understanding; Language.

\footnotetext{
1 Doutorando em Filosofia pela Universidade Federal do Piauí (UFPI), Teresina - PI, Brasil. Professor Substituto da Universidade Estadual do Piauí (UESPI), Parnaíba - PI, Brasil.
}

SOUSA, Paulo Thiago Alves. A constituição hermenêutica filosófica das ciências humanas em Hans-Georg Gadamer. Griot : Revista de Filosofia, Amargosa - BA, v.20, n.2, p.224-243, junho, 2020. 


\section{Introdução}

O ponto de inspiração de Gadamer esteve inicialmente marcado no esforço diltheyniano de fundar filosoficamente as ciências humanas, ou, como apresentou em $O$ problema da consciência histórica (2003), que a vontade de Dilthey foi de descobrir um fundamento novo e epistemologicamente consistente, o que pode ser entendido uma tentativa de completar a crítica da razão pura de Kant com uma crítica da razão histórica. No intuito de superar o enredamento no historicismo diltheyniano, Gadamer procurou pensar a experiência da verdade como participante de uma ontologia fundamental proposta por Heidegger. A Hermenêutica filosófica gadameriana em Verdade e Método muito deve ao pensamento heideggeriano, principalmente esboçado na obra Ser e tempo.

O presente artigo focalizará a relação que as ciências humanas mantêm no âmbito da experiência histórico-hermenêutica. No referido âmbito, os conceitos de fusão de horizontes e consciência histórica constituem instâncias fundamentais da compreensão hermenêutica, são a partir delas que Gadamer evidenciará o caráter de linguagem ou linguisticidade (Sprachlichkeit) que mantém a relação dialógica do intérprete e seu objeto de focalização. Este artigo argumenta, ainda, por meio da obra Verdade e Método que Gadamer pensou a experiência da compreensão histórica como experiência do diálogo, e essa afirmação pode ser constatada na estrutura da pergunta e resposta.

$\mathrm{Na}$ primeira parte do presente estudo apresenta a crítica de Gadamer a valorização do método científico como respostas para o problema do conhecimento. $O$ filósofo alemão critica a intenção positivista de alavancar o método indutivista das ciências naturais paras as ciências humanas. Para Gadamer é preciso ter em pauta a sutil expressão das ciências humanas, isso porque as perspectivas daquela não podem ser exauridas em conclusões estatísticas ou instrumentalizações passiveis de coordenação. As ciências humanas lida com a contingente ação humana que se desdobra na história. Por isso que para Gadamer é necessário um outro tipo de comportamento compreensivo que não leva em consideração apenas a destreza em remanejar métodos, para de uma sensibilidade para o intérprete. Com isso Gadamer lança mão principalmente do conceito de "tato" em Helmholtz, como também, lança uma aproximação do trabalho da interpretação ao conceito de jogo.

Na segunda parte, a hermenêutica da faticidade de Heidegger aparece como a grande impulsionadora da hermenêutica da faticidade de Gadamer. Os conceitos de hermenêutica da facticidade e analítica existencial do Dasein recuperam para a compreensão seu caráter existencial, ou seja, pensado como modo de ser do Dasein no mundo e com os outros. A partir da retomada à hermenêutica heideggeriana, Gadamer pensou a ressignificação da hermenêutica das ciências humanas em conjunto com a tarefa universal de uma hermenêutica filosófica com fim de realizar a experiência ontológica.

Por fim, três conceitos inter-relacionados são muito importantes para Gadamer no desenvolvimento da sua hermenêutica filosófica aplicada às ciências humanas, são eles: círculo hermenêutico, consciência histórica e a linguagem. Nesse terceiro ponto apresenta-se a convergência desses conceitos para desenvolver o papel dialógico que constitui a relação do intérprete com o interpretado. O círculo hermenêutico é revitalizado na medida que a compreensão refaz o sentido do interpretado, conduzindo a novas possibilidades. Conclui-se que o objetivo central de Gadamer nessa nova reorientação do sentido hermenêutico busca efetiva o desenvolvimento da consciência histórica efeitual. Consciência que se desdobra na práxis atuante do diálogo e da compreensão radical sobre a historicidade. 


\section{Os caminhos críticos e não-metodológicos para as ciências humanas}

Na Modernidade, o método se tornou a capacidade que o conhecimento desenvolveu para estabelecer regularidades e apresentar resultados. Partindo da história, a influência do pensamento moderno metodológico se estendeu do século XVII até as primeiras décadas do século XX. A influência de pensadores modernistas, como Francis Bacon e René Descartes, como também de Iluministas e Positivistas, nortearam as perspectivas epistemológicas do ponto de vista de uma racionalidade científica, fomentando a ideia de progresso e emancipação do ser humano pela razão liberada de suas obscuras verdades. A versão demarcatórica de ciência em Bacon (2007) alçou a verdade científica a partir da eliminação dos "ídolos" que assombravam a conduta e o aprofundamento epistemológico do cientista. A influência de Descartes (2011) apontou para o conhecimento humano sobre condições seguras e corretas, estabelecendo o âmbito e os limites do pensamento e, para tal propósito, deveria guiar-se pelo método de procedimento no nível das ciências naturais. No século XVIII, o projeto iluminista deixou bem claro seu campo de embate com o passado ou a tradição, reconhecendo nesta, o lugar do fanatismo e da superstição, exaltando o poder da razão humana e tendo como missão deste projeto avivar ou iluminar os diversos campos do saber e da vida humana. E a influencia do positivismo reclama o lugar adequado da colocação da verdade para o âmbito das ciências naturais em detrimento das especulações da metafísica, da estética ou teologia.

A Modernidade confia, sem crítica alguma, no poder do método para estabelecer verdades autocertificadas. $O$ preço a ser pago, se for visto como uma perda tangível, é que a dependência antiga sobre a qual a autoridade textual (e escritural) é colocada em dúvida, e aquelas atividades costumeiras, originalmente sem respaldo racional para mantê-las ou dar a elas respeitabilidade filosófica, são rejeitadas. As maneiras tradicionais de fazer as coisas, dependendo geralmente de práticas costumeiras, são anátemas à era da racionalidade científica. (LAWN, 2010, p. 52).

Por que Gadamer insistiu que é necessário priorizar, ao longo da obra Verdade e Método, uma hermenêutica das ciências humanas, em vez de propor uma nova metodologia para elas? Como realizar essa tarefa de ressignificação das ciências humanas, sem que ela recaia na dinâmica das ciências naturais? A primeira questão se desenha na parte introdutória de Verdade e Método, em que Gadamer destacou que a autorreflexão lógica das ciências humanas no século XIX esteve dominada pelo modelo das ciências naturais, lembrando que foi com John Stuart Mill $^{2}$ que se popularizou esta expressão, assim como a reconheceu como perpassada pelo método indutivo ${ }^{3}$, e este último, sendo a base de toda ciência experimental. Esta invocação do método indutivo dentro das ciências do espírito significou analisar os processos individuais, os quais constituem propriamente uma síntese explicativa da ação humana ao longo da história, buscando uniformidade, regularidade e legalidade e, desse modo, transformando as contingencias em determinações datadas e passíveis de serem reproduzidas.

Gadamer contra argumentou o indutivismo radical de Mill, na tentativa de esclarecer que o esforço de determinar meandros mais específicos para a realidade humana, encontraria expostos a erros e limitações. Para isso, refletiu sobre tais limitações, mas propriamente nas

\footnotetext{
${ }^{2}$ Cf. A lógica das ciências morais: "Corretamente concebida, a doutrina da Necessidade Filosófica é simplesmente esta: sendo dados os motivos presentes à mente de um indivíduo e sendo dado, igualmente, o caráter e a disposição do indivíduo, a maneira pela qual ele irá agir pode ser inferida infalivelmente; se conhecêssemos completamente a pessoa e todos os induzimentos que atuam sobre ela, nós poderíamos predizer sua conduta com a mesma certeza com que podemos predizer qualquer evento físico [...]". (MILL, 1999, p. 34).

3 Segundo Chalmers (1993, p. 25): “A resposta indutivista é que, desde que certas condições sejam satisfeitas, é legítimo generalizar a partir de uma lista finita de proposições de observação singulares para uma lei universal”.
} 
ciências naturais, pensando, por exemplo, na metereologia, que mesmo confiável em uniformidade, regularidade e legalidade, possuem dados incompletos e, consequentemente, inseguras previsões. Se o método indutivo ainda é passível de falibilidade nas ciências da natureza, supõe-se que sua incorporação no modus operandis nas ciências humanas constitui mais que questionável, inviável. A objeção se faz, principalmente, porque o domínio epistemológico do positivismo não poderia metodologicamente regular o conhecimento cultural, histórico, social, que constitui o "palco" extremamente instável do desenvolvimento humano, mas que propriamente tal instabilidade é o motor da experiência de verdade.

\begin{abstract}
A experiência do mundo sócio-histórico não se eleva no nível de ciência pelo processo indutivo das ciências da natureza. $O$ que quer que signifique ciência aqui, e mesmo que em todo conhecimento histórico esteja incluído o emprego da experiência genérica no respectivo objeto de pesquisa, o conhecimento histórico não aspira tomar o fenômeno concreto como caso de uma regra geral. $O$ caso individual não se limita a confirmar uma legalidade, a partir da qual, em sentido prático, se poderia fazer previsões. Seu ideal é, antes, compreender o próprio fenômeno na sua concreção singular e histórica. Por mais que a experiência geral possa operar aqui, o objetivo não é confirmar nem ampliar essas experiências gerais, para se chegar ao conhecimento de uma lei - por exemplo, como se desenvolvem os homens, os povos, os estados -, mas compreender como este homem, este povo, este estado é que veio a ser; dito genericamente, como pode acontecer que agora é assim. (GADAMER, 2015, p. 38-39).
\end{abstract}

Como se pode constatar, a reabilitação das ciências humanas em Verdade e Método tem como primeiro momento uma situação crítica em face ao reducionismo científico e, ao mesmo tempo, tal postura crítica foi retomada por Gadamer para reavaliar a posição de pensadores como Herman Helmholtz, J.G. Droysen e destacadamente, W. Dilthey, que se propuseram a encontrar uma especificidade para as ciências humanas. No entanto, o que resultou foi, no entender de Gadamer, um retorno ao método-científico-natural e ao empirismo reducionista da Lógica de Mill. Apesar de ser contraditório o argumento da busca pela especificidade, o que estes pensadores pareceram concordar foi que existia uma clara separação ou um plano específico entre a investigação dos fenômenos naturais e a compreensão da história.

É necessário evitar a interpretação deste empenho contra o método apenas como um esforço de circunscrição ou especificação do domínio epistemológico, interpelando-se e respondendo qual o estatuto de demarcação para as ciências. Todavia, em Gadamer, tornou-se um esforço filosófico repensar criticamente a realização do sentido e o destino que toma a existência humana a partir de seus modos de interpretação e de verdade. Trata-se, principalmente, de repensar a tarefa da compreensão nas ciências humanas, tomando como ponto de partida uma hermenêutica que seja abertura de verdades.

Outro ponto que merece ser esclarecido é que a ressignificação filosófica das ciências humanas em Gadamer não pretendeu refutar a validade epistemológica da ciência e sua importância para o saber, mas fazer com que uma concepção universalizante de método fosse abandonada. Grondin advertiu, nesse sentido, que aqui não constituiu uma oposição definitiva e integral ao saber metódico, mas sim, a sua imposição como único modelo de conhecimento que torna os seres humanos cegos a outros modos de saber: "Uma reflexão que quisesse fazer justiça à verdade das ciências humanas, reflexão decorrente daquilo que podemos chamar uma "hermenêutica", não seria necessariamente uma metodologia" (GRONDIN, 2012, p. 64). Na mesma noção de pretensão à universalidade, constaram Lawn e Keane (2011) no The Gadamer dictionary: "Parte da ilusão do método é sua alegada aplicabilidade universal" (LAWN; 
KEANE, 2011, p. 92 $)^{4}$. Esses autores destacaram que o objetivo de Gadamer foi combater a ortodoxia, a obscuridade e a distorcida relação com a verdade. Weinsheimer (1985) comparou o método a uma "morada" defensiva contra o outro, o estranho (Fremdheit). O método seria uma resposta prioritária que sugere uma situação de desabrigamento do mundo: "Está em casa significa pertencer, viver em torno daquilo que é familiar, auto-evidente, e sem obstrução; este contrário, Fremdheit, consiste na cisma entre o passado e o presente, eu e outro, si mesmo e mundo" (WEINSHEIMER, 1985, p. 04)5. Porém, o método como elemento contra o estranhamento não é algo específico das ciências naturais, como ressaltou Gadamer. Na própria história do desenvolvimento da hermenêutica, a pretensão de Schleiermacher esteve perpassada pela vontade de extinguir a experiência da estranheza (Fremdheit) e dos mal-entendidos, e estes devem ser ultrapassadas em prol do sentido novo e universal. Em vez disso, a tese hermenêutica em Gadamer necessita desse elemento estranho, ele não é somente um ponto de partida, mas representa o universo compreensivo com que o intérprete dialoga.

Dividida em três momentos, Verdade e Método constitui um esforço de realizar a experiência da verdade que não seja apropriação metodológica, nesse sentido, a partir de Schmidt, poder-se-ia dizer que a referida obra se situa em torno de três momentos: "[...] experiência da verdade na arte, a experiência da verdade na compreensão das ciências humanas e na fundamentação ontológica da hermenêutica na linguagem" (SCHMIDT, 2006, p. 141).

Nesta primeira parte da obra Verdade e Método, intitulada A liberação da questão da verdade a partir da experiência da arte se destaca a recondução anti-metodológica à tradição do humanismo, calcada no conceito de formação (Bildung), como também, a análise que Gadamer fez da retomada ao processo de metodologização e estetização dos conceitos de juízo, gosto e da experiência da arte a partir do conceito de jogo. Para Grondin, o caminho levado por Gadamer em face da estética seria um desvio, ou seja, o filósofo alemão estava mais preocupado com uma crítica à abstração da consciência estética: "Apesar de todas as concepções positivas sobre a arte, a parte introdutória de Verdade e Método oferece mais uma anti-estética do que uma estética" (GRONDIN, 1999, p. 185).

Para entendermos a crítica anti-estética é importante compreender o enfrentamento do método pela tradição do humanismo recuperado por Gadamer. Como lembrou Weinsheimer, apesar de Verdade e Método ter fortemente uma análise crítica sobre a problema metodológico, Gadamer não pretendeu definir o que seja o método, enumerar pressuposições ou elaborar suas implicações, mas pensar um estatuto autônomo para as ciências humanas, em que, “"[...] antes, ele prossegue imediatamente para uma história de caminhos não-metodológicos para a verdade que se tornaram disponíveis através da tradição humanista" (WEINSHEIMER, 1985, p. 01) O legado da tradição humanística recuperado por Gadamer está no conceito de formação, que traduz o termo alemão Bildung, mas também por ser traduzido por educação ou cultura. Dentro da história da formação, Gadamer identificou em Herder o pensador pioneiro da ressignificação semântica para a Bildung, entendendo que nele se situou a determinação fundamental da formação, ou seja, ela possuía o objetivo educacional e cultural da elevação do espírito, que é via para o universal da verdade humana em oposição ao particular.

Contudo, foi na revisitação de pensadores como Humboldt, Hegel e, sobretudo, Helmholtz, com o desenvolvimento da Bildung, a partir do conceito de "tato", que Gadamer se

\footnotetext{
${ }^{4}$ No original: "Part of the illusion of method is its alleged universal applicability".

5 No original: "To be at home means to belongs, to live in sorroundings that are familiar, self-evident, and unobtrutive; its contrary, Fremdheit, consists in the schism beteween past and presente, I and others, self and world".

${ }^{6}$ No original: "Rather, he proceeds immediately to a history of nonmethodical avenues to truth which have become avilable through the "humanistic tradicion".
} 
orientou para questionar a busca do método como garantia da validade universal e refletir sobre quais condições novas se poderiam pensar as ciências humanas.

Helmholtz destacou que tanto as ciências naturais como as ciências humanas possuíam horizontes próprios de abordagem, em que a primeira se caracterizava pelo método de indução lógica, regras e leis, visando a validade universal, enquanto a segunda possuía o que ficou conhecido como um sentimento psicológico de "tato". Compreender as ciências humanas a partir desse elemento de formação que constitui o "tato" é permitir ao espírito uma mobilidade livre, que compreende e ressignifica, reconduzido a olhos novos: [...] entendemos uma determinada sensibilidade e capacidade de percepção de situações, assim como o comportamento que temos nessas situações quando não possuímos nenhum saber baseado em princípio universal" (GADAMER, 2015, p. 52).

Nesse contexto, para Helmholtz, o conceito de "tato" ofereceu para as ciências humanas o desenvolvimento de uma formação que é um modo de conhecer e uma forma de ser no mundo e que se alicerça para a formação de uma consciência estética e na formação da consciência histórica. Como analisou Gadamer, a mediaticidade da consciência se relaciona com a imediaticidade do sentido para compor o "tato", pois o que está em jogo é saber avaliar e discernir a especificidade do caso, trazendo consigo uma intuição, uma sensibilidade que capacite a interação com um sentido que não é universal, mas plausível ou possível. É nesse contexto que possuir "tato", na estética, é pautar-se em um saber ou sensibilidade que distinga o belo do feio, saber ter "tato" histórico é saber o que é possível ou não é possível para uma época: "Helmholtz fala aqui de uma 'intuição instintiva', que brota de uma sensibilidade instintiva, ou tato, para o qual, todavia, não existem regras definidas" (GRONDIN, 1999, p. 182).

Para Grondin, o parceiro principal de diálogo com Gadamer em Verdade e Método seria Helmholtz, o que poderia soar exagerado, pois toma sua razoabilidade no modo que Gadamer utilizou o conceito de "tato" de modo explícito ou implícito em sua reflexão hermenêutica. Assim, um primeiro caminho para opor ao método das ciências humanas, como também fazer oposição ao historicismo, estaria no conceito de "tato". Grondin ainda salientou que Helmholtz e não Dilthey, foi um silencioso defensor de uma hermenêutica das ciências humanas, já que Dilthey, para Gadamer, recaiu naquilo que chamou de discrepância teórica rumo ao historicismo. Em uma passagem pontual de Verdade e Método, pode-se constatar as relações entre Gadamer e Helmholtz:

A reflexão sobre o conceito de formação, tal como fundamenta as reflexões de Helmholtz, nos faz recuar na história desse conceito Precisamos acompanhar um pouco esse contexto se quisermos que o problema apresentado à filosofia pelas metodologias do espírito rompa a estreiteza artificial que comprime a metodologia do século XIX. O conceito da ciência e conceito de método a ela subordinado não é suficiente (GADAMER, 2015, p. 54).

A retomada de Gadamer ao conceito anti-metodológico de "tato" percepcionado por Helmholtz e as reflexões deixadas pela tradição humanística ao longo de seu percurso histórico, leva progressivamente ao sentido de compreensão do como se deu a decadência dessas perspectivas para o fortalecimento progressivo de uma concepção metodológica. Se existe uma forma de explicar tal derrocada da tradição humanística, estaria na estetização ou subjetivação dos conceitos de juízo e de gosto, que foram muito influentes naquela tradição.

A questão posta por Gadamer se localizou na concepção de Kant em sua teorização acerca da temática na obra Crítica do juízo, em que o filósofo afirmou que, no contexto da formação do gosto, existiria um momento apriorístico que está para além da universalidade empírica e isto repercutiria no esforço próprio e pessoal que se eleva pela capacidade de 
reconhecer as pistas para o um modelo a priori, o que estabelece que não é a preferência pessoal que decide, antes o julgamento estético está submetido a uma norma supraempírica. As consequências da justificação deixada por Kant, no entender de Gadamer, foi negar ao gosto qualquer significado cognitivo sob o objeto julgado: “É um princípio subjetivo, ao qual ele reduz o senso comum. Nele não se reconhece nada dos objetos que são julgados como belos; apenas se afirma que a eles corresponde a priori um sentimento de prazer no sujeito" (GADAMER, 2015, p. 84). Para Grondin, relegar o juízo de gosto a uma simples sensação subjetiva constituiu o princípio para a força do método científico e, ao mesmo tempo, o enfraquecimento de outras possibilidades que se encontravam na intuição subjetiva do gosto e, com esse enfraquecimento, as ciências humanas viram ciências metodológicas.

O que satisfaz aos parâmetros objetivos e metódicos das ciências naturais, vale agora
como meramente "subjetivo" ou "estético", isto é, afastado do reino do conhecimento.
Enquanto a subjetivação kantiana do conceito de gosto "desacreditou qualquer outro
conhecimento teórico, além daquele das ciências do espírito no sentido de se orientarem
pela metodologia das ciências naturais". Com isso, a tradição humanística, na qual as
ciências do espírito ainda poderiam reconhecer-se, foi abandonada e ingressou-se no
caminho da estetização e subjetivação do juízo (GRONDIN, 1999, p. 184).

O caminho buscado por Gadamer teve na recuperação do conceito de jogo o objetivo de repensar o lugar de nossa subjetividade. No entender de Almeida, é necessário compreender sua "[…] produtividade para a explicação ontológica da experiência hermenêutica" (ALMEIDA, 2002, p. 183). Seguindo Almeida, poderia dizer que o conceito de jogo em Verdade e Método tem como contexto discutir " $[. .$.$] a verdade da arte e sua autonomia frente à consciência estética. \mathrm{O}$ conceito de jogo assume ali um caráter modelar para a compreensão de sentido hermenêutico da substancialidade que determina toda subjetividade". (ALMEIDA, 2002, p. 183-184).

Gadamer analisou, de forma permanentemente fenomenológica, o conceito de jogo em Verdade e Método, pensando tal conceito como modelo estrutural para a explicação da compreensão. No início de sua análise, evidenciou que o conceito de jogo é diverso do conceito de subjetividade. A objeção de Gadamer se explica pelo fato de que não é pela via da reflexão de quem joga que pode ser encontrada alguma resposta para a natureza do jogo, o que se infere daí é que ele não corresponde ao "[...] comportamento, nem ao estado de ânimo daquele que cria ou daquele que desfruta do jogo e muito menos à liberdade de uma subjetividade que atua no jogo, mas o próprio modo de ser da própria obra de arte" (GADAMER, 2015, p. 154).

$O$ que Gadamer pretendeu esclarecer é que não são as diversas consciências que dominam o jogo, não existe uma regra que perpassa e molda a forma de jogar e compreender. Nas palavras do filósofo alemão: "O sujeito do jogo não são os jogadores. Ele simplesmente ganha representação através dos que jogam o jogo" (GADAMER, 2015, p. 155). Gadamer aplicou o conceito de jogo para as ciências humanas, nesse sentido, o jogar constitui um fenômeno cultural, e disso, pode ser compreendido que o jogar deixa antever uma significação, pode ser o momento do desvelamento de verdades ocultas.

Em seu sentido amplo, o jogo goza de uma independência, ele possui sua natureza própria onde nenhum ser-para-si consegue determinar seu horizonte de abrangência. No jogo, se realiza o encontro com a verdade, mas que é possível a partir do momento em que nos deixamos levar por ele. Grondin explicou que aquele que joga se encontra transportado para uma realidade que o ultrapassa, pois, "nesse jogo, somos menos aqueles que dirigem e mais aqueles que são levados, encantados pela obra, que nos leva a participar de uma verdade superior" (GRONDIN, 2012, p. 65). 
Não que a subjetividade no jogo esteja em vias de extinguir-se, ao contrário, ela só diminui sua vigência, o sujeito é tomado por aquilo que está engajado, seja em uma partida de tênis, na dança, ao tocar um instrumento ou em recitar um poema, estes momentos não são em si mesmos, mas são possibilidades de transformação do sentido que o sujeito tem sobre as coisas, sobre si mesmos e outros. Grondin se referiu a essa tomada da subjetividade como um dobrar-se "[...] àquilo que a obra, em toda a sua objetividade, lhe impõe: o sujeito se encontra engajado em um encontro que o transforma" (GRONDIN, 2012, p. 66). Esse engajamento é um vaivém em que o jogo se comporta, sem determinações, sem sentido fixo, mas é sempre uma mobilidade e uma revelação da verdade:

Fica claro que o jogo representa uma ordem na qual o vaivém do movimento do jogo se produz como que por si mesmo. Faz parte do jogo o fato de que o movimento não somente não tem finalidade nem intenção, mas também não exige esforço (GADAMER, 2015, p. 158).

“O 'sujeito" da experiência da arte, o que fica e permanece, não é a subjetividade de quem a experimenta, mas a própria obra de arte" (GADAMER, 2015, p. 155). Na verdade, o que corresponde entender a natureza do jogo está na experiência da arte, que se desvia de qualquer nivelamento da subjetivação, não é o sujeito que transforma a concepção da arte, antes é a própria experiência na arte que transforma aquele que experiência.

Pensar as ciências humanas a partir do conceito de jogo e arte corresponde defender a tese de que o pesquisador ou intérprete não eleva sua subjetividade em relação a outras subjetividades, ou mesmo, reduz-se apenas a um telespectador científico. Uma vez tomado pelo jogo ele deixa se levar pelas possibilidades de significações, não só algo muda fora dele mas ele mesmo se modifica. Desse modo que as ciências humanas estariam mais próximas a experiência da arte, não há como reduzir o fazer artístico, da mesma forma não há como delimitar o campo de estudo do pesquisador. A verdade que se desvela não depende de nós mas do deixar falar da expressão cultural.

\section{Acompanhando a ontologia-hermenêutica de Heidegger}

A relação entre Gadamer e Heidegger constituiu um passo importante dentro da história da hermenêutica das ciências humanas e, com isto, se quer inicialmente afirmar uma via de ruptura com o contexto científico-metodológico da hermenêutica, principalmente aquele que foi ajudado por Schleiermacher e Dilthey. Como consequência deste primeiro momento, a hermenêutica filosófica desenvolvida por Gadamer, representou um desdobramento da hermenêutica da facticidade de Heidegger, a hermenêutica gadameriana pode entreter os horizontes conceituais da ontologia fundamental e da analítica existencial do Dasein para a questão das ciências humanas percepcionada anteriormente por Dilthey. $O$ problema hermenêutico, para Gadamer, encontrou inicialmente como dificuldade a ser superada, a direção do conceito histórico de Dilthey que estava mais próximo do idealismo especulativo, também analisou que foi Heidegger, embasado pela fenomenologia, quem libertou da intenção filosófica de Dilthey, isto, porque viu a inadequação do conceito de substância para o ser e para o conhecimento histórico.

Não seria um equívoco compreender a problemática de Gadamer trazida aqui na esteira do pensamento de Dilthey e Heidegger, mas, como destacou Grondin, o pensamento heideggeriano tem por objetivo renovar a compreensão do problema diltheniano, ou seja, de que apenas a metodologia seria o caminho para a questão da verdade das ciências humanas: " $O$ propósito inicial de Gadamer é justificar a experiência de verdade das ciências humanas (e do 
desenvolvimento em geral) partindo da concepção "participativa' do entendimento" (GRONDIN, 2012, p. 63).

Heidegger retomou a Fenomenologia de Husserl para renovar toda a filosofia de seu tempo e, aprofundando as descobertas fenomenológicas, centrou suas investigações nas noções do "ser" e da "existência". Diferentemente de centrar na consciência à procura do sentido da relação cognitiva com os objetos, Heidegger procurou alargar além da consciência, considerando esta como propriedade auxiliar, cujo sentido implícito do ser em geral é preciso esclarecer ou desvelar. Como diria Lévinas em Descobrindo a existência com Husserl e Heidegger (1997, p. 76), “é o abandono da noção tradicional da consciência como ponto de partida, com a decisão de procurar a base da própria consciência no acontecimento fundamental do ser - na existência do Dasein". Heidegger fundamentou no ser a condição primeva de toda consciência e de todas as relações existentes no mundo, com coisas e pessoas.

Uma nova perspectiva para a hermenêutica foi reconduzida por Heidegger, quando este ousou confundir a atitude compreensiva com a existência fática do ser humano. $\mathrm{O}$ compreender não é um momento instrumental da abertura para o verdadeiro, não se comporta como epifenômeno, mas constitui o próprio fenômeno, um modo de ser irremediável. Como bem observou Grondin, em Heidegger aconteceu a transformação filosófica da hermenêutica que antes era método para uma atitude fenomenológica do despertar para o ser, e decorrente disto, incidirá o fenômeno da compreensão sobre a própria existência, deixando de focalizar apenas a interpretação textual e servir como instrumento para a epistemologia. Tal hermenêutica teria a facticidade como plano fundamental da compreensão, nomeando-se como a existência concreta, individual e finita que "[...] não é para nós um objeto, e sim uma aventura na qual somos projetados e para a qual podemos despertar de maneira expressa ou não" (GRONDIN, 2012. p. $38)$.

Antes mesmo de sua grande obra Ser e Tempo, publicada em 1927 (que propriamente já é uma obra acerca do "despertar" para o ser, partindo da analítica existencial), Heidegger dedicou-se ao conceito de facticidade, fazendo temática central de umas das preleções dadas por ele na Universidade de Friburgo, em 1923, cujo título ficou conhecido como Ontologia (hermenêutica da facticidade), onde se referiu ao conceito de facticidade como sendo "[...] a designação para o caráter ontológico de nosso ser-aí próprio. Mais especificamente, a expressão significa: esse ser aí em casa ocasião [...]" (HEIDEGGER, 2012, p. 13). É, nesse sentido, que a hermenêutica é o despertar para o caminho do ser que está aí em cada momento da nossa cotidianidade, ao mesmo tempo que é "[...] o modo unitário de abordar, concentrar, acessar a ela, isto é, de questionar e explicar a facticidade" (HEIDEGGER, 2012, p. 15).

A obra de Heidegger, Ser e Tempo, publicada em 1927, cuja tese se ler "ser é tempo", foi desenvolvida a partir do não desdobramento da temporalidade, entendida como consciência ou eu-originário transcendental, em outras palavras, uma clara tentativa de rompimento com o todo subjetivismo da filosofia mais recente, principalmente aquela de cunho husserliano, evidenciando uma temporalidade que aparece como determinação ontológica da subjetividade, o Ser se dá na compreensão fático-temporal como ser lançado no mundo:

Na verdade, a renovação da questão do ser, que Heidegger tomou como tarefa, significa que, em meio ao 'positivismo' da fenomenologia, ele reconheceu o problema fundamental da metafísica ainda não resolvido, problema que, na sua culminação extrema, ocultou-se no conceito de espírito tal como foi pensado pelo idealismo especulativo. Por isso, a tendência de Heidegger é orientar sua crítica ontológica contra o idealismo especulativo, passando pela crítica a Husserl. Em sua fundamentação da hermenêutica da 'facticidade', ele ultrapassa tanto o conceito de espírito, desenvolvido pelo idealismo 
clássico, como o campo temático da consciência transcendental, purificado pela redução fenomenológica" (GADAMER, 2015, p. 346).

Como já se pode constatar a facticidade assume o lugar de uma referência onde o ser humano está lançado em suas próprias possibilidades, estando na trilha do sempre aberto do ser. O ente humano é designado como ser-aí, expressão cunhada por Heidegger a partir da junção das palavras alemãs $D a$ (aí) e Sein (ser). O Da-sein ou ser-aí corresponde à existência humana que pode colocar a questão do sentido do ser. Para Heidegger, o Dasein é Ser deste mundo, pois a sua essencialidade é o desdobramento da sua experiência compreensiva, engajada na existência, toda sua obra, seu emprenho de vida, corresponde de algum modo ao ser: "A compreensão de ser é em si mesma uma determinação de ser da presença. $O$ privilégio ôntico que distingue a presença está em ela ser ontológica" (HEIDEGGER, 2012, p. 48). É o Dasein que retoma a pergunta sobre o seu próprio ser, isto se deve, ao fato de que o ser humano não "é", mas "existe", ou seja, não está simplesmente exposto na existência como um objeto dado. Daí pensar seu caráter arremessado ou lançado na existência, tornando-se projeto e possibilidade de transcender-se em cada ocasião.

\begin{abstract}
O estar-lançado não só não é um "feito pronto" como não é um fato acabado. Pertence à facticidade da presença ter de permanecer em lance enquanto for o que é e, ao mesmo tempo, de estar envolta no turbilhão da impropriedade do impessoal. Pertence à presença que, sendo, está em jogo o seu próprio ser, o estar-lançado no qual a facticidade se deixa ser fenomenalmente. A presença existe faticamente (HEIDEGGER, 2012, p. $244)$.
\end{abstract}

O Dasein é projeto na medida que significa que estar-lançado num mundo dado de possibilidades e também encontra certas determinações, ao mesmo tempo que está entregue, "abandonado", pode inquietar-se com a existência, projetando para além de si. Esse projetar é a compreensão do Dasein que existe além de si como ser do mundo participante de sua história, perpassado pelo seu passado e podendo projetar seu futuro, e é nesse ponto que a verdade constitui uma experiência que se desvela no seio da situação fática, articulada com a própria historicidade.

\begin{abstract}
Assim o compreender, como estrutura projetiva, que investe o ente, e a disposição, como investimento da situação fáctica em meio à totalidade do ente, constituem ambos a possibilidade lançada (geworfen möglichkeit) do ser-no-mundo que a angústia revela, em meio ao ente que refugimos, caídos no circuito protetor e familiar da lida cotidiana, absorvidos nas ações do dia-a-dia, que instrumentalizam o Dasein em função das coisas com que se preocupa e do ser-em-comum no qual se espelha (NUNES, 1992, p. 156).
\end{abstract}

Mas como a hermenêutica de Gadamer se aproximou do pensamento heideggeriano da hermenêutica da facticidade? A questão pode ser respondida logo por meio de uma objeção, pois, Gadamer havia se convencido de que, desde o princípio, para Heidegger, a problemática e a hermenêutica histórica estiveram orientadas para uma finalidade ontológica, ou seja, uma renovação geral da questão do ser que estava velada no ostracismo e no esquecimento do conhecimento da humanidade. Apesar das questões das ciências do espírito e das aporias do historicismo não serem momentos privilegiados na reflexão de Heidegger, elas estão situadas, de um modo ou de outro, na questão da renovação do sentido do ser. E, para Gadamer, esta renovação ontológica significou liberar um caminho promissor ante o labirinto conceitual das ciências do espírito que haviam deixado Dilthey e Husserl. Portanto, o caminho para a nova hermenêutica das ciências humanas vinculou-se ao desenvolvimento da analítica existencial do 
Dasein heideggeriano, o que pode ser manifesto dessa nova posição é que a compreensão das ciências humanas estaria revestida pelo "[...] caráter de projeto que reveste toda compreensão e pensou a própria compreensão como movimento da transcendência, da ascensão acima do ente" (GADAMER, 2015, p. 348).

Em Heidegger, Gadamer alargou os horizontes das ciências humanas, ele a recoloca na conexão entre vida que sempre implica consciência e reflexividade, mas uma reflexividade como possibilidade de avançar sempre a partir de sua situação atual. A valência ontológica que adquire as ciências humanas é, justamente, a possibilidade de autotranscendência, que constitui a realização de uma consciência histórica efeitual que interroga pelo próprio estatuto do conhecimento e está sempre acessível.

\begin{abstract}
As ciências humanas adquirem assim uma valência "ontológica" que não poderia permanecer sem consequências para sua autocompreensão metodológica. Se o Vestehen é o aspecto fundamental do in-der-Welt-sein humano, então, as ciências humanas encontram-se mais próximas da autocompreensão humana do que as ciências naturais. A objetividade destas últimas não é mais um ideal de conhecimento inequívoco e obrigatório. As ciências humanas contribuem para a compreensão que o homem tem de si mesmo, embora não se igualem às ciências naturais em termos de exatidão e objetividade, e se elas assim o fazem é porque possuem, por sua vez, o seu fundamento nessa mesma compreensão (GADAMER, 2003, p. 12).
\end{abstract}

Ainda no ensaio $A$ universalidade do problema hermenêutico, Gadamer retomou o problema do historicismo, afirmando que a "consciência histórica" em Dilthey, com sua pretensão a uma objetividade histórica, é acometida de dificuldades características e uma delas é da insuficiência do método histórico não revelar toda a realidade ou totalidade da experiência: “[...] a ciência histórica, só revela uma parte do que é a verdadeira experiência, isto é, do que significa para nós o encontro com a tradição histórica, limitando-se a conhecer, assim, apenas uma configuração alienada" (GADAMER, 2012, p. 124). Portanto, propõe o desenvolvimento de uma "consciência hermenêutica" como possibilidade efeitual, contrapondo a redução teóricocientífica que sofreu durante muito tempo a compreensão histórica para uma postura crítico filosófica. Afirmou Gadamer em O problema da consciência histórica.

Esse era o preconceito ingênuo do historicismo, que acreditava poder alcançar o terreno da objetividade histórica através de um esforço para se colocar na perspectiva da época estudada e pensar com os conceitos e representações que lhes eram "próprias". Trata-se, na verdade, de considerar a "distância temporal" como fundamento de uma possibilidade positiva e produtiva de compreensão (GADAMER, 2003, p. 67):

As bases da estrutura existencial do pro-jeto lançado está na fundamentação das ciências humanas. Elas possuem como caminho da compreensão os vínculos concretos que representam a cultura, a moral, a tradição; em outras palavras, decorre da investigação das condições históricas concretas. Gadamer aplica a relação entre as ciências humanas e a tradição, pensando que não podemos nos desvencilhar desta última, pois nosso comportamento se deve ao nosso passado, nós somos seres históricos e participantes da cultura. Para Gadamer, uma atitude autêntica estaria no desenvolvimento daquilo que é a cultura, nossa historicidade: “[...] um desenvolvimento e uma continuação daquilo que reconhecemos como sendo o elo concreto entre nós" (GADAMER, 2003, p. 44). A tradição sobrevive em nós como um motor, ela é um fenômeno de produção do conteúdo transmitido. Desse modo, que a hermenêutica das ciências humanas gadameriana propõe é que a tradição e a pesquisa histórica são unidades efetivas e, desse modo, a consciência histórica que se configura não constituiria um fenômeno novo, mas 
uma transformação revolucionária no interior do comportamento do ser humano com seu passado.

As questões desenvolvidas até aqui abrem novos caminhos conceituais para compreender os meandros da hermenêutica das ciências humanas. No próximo tópico que dar-se-á um passo a mais conduzido pelo desenvolvimento da consciência histórica efeitual gadameriana. Este conceito constitui a marca do pensamento gadameriano, aplicado juntamente com o conceito de círculo hermenêutico e fusão de horizontes e poderemos a partir desses aspectos encontrar o caráter de linguagem que sobrevive, de modo ávido, principalmente, na relação do intérprete ou pesquisador com seu objeto de estudo.

\section{Círculo hermenêutico, consciência histórica e a linguagem a partir da fusão de horizontes}

Com a influência heideggeriana sobre a hermenêutica de Gadamer, a compreensão não pode ser mais vista como um conceito ocasional que chega para realizar o sentido quando a obscuridade do texto se impõe, mas a compreensão enquanto inevitabilidade é o próprio modo de ser-no-mundo do Dasein ou do intérprete das ciências humanas, que tem em torno de si sua própria historicidade e condições fáticas, e é nesta condição que realiza sua abertura para o sentido do ser aí. Face a essa constatação, Gadamer defendeu a realização da compreensão das ciências humanas com o objetivo de desenvolver aquilo que ele chamou de uma contínua consciência histórico-efeitual (Wirkungsgeschichtliches Bewusstsein) ${ }^{7}$, que se realizasse nas possibilidades do círculo hermenêutico e na fusão de horizontes. Esta contínua consciência histórico-efeitual (ponto central do pensamento gadameriano) constitui o engajamento filosófico do intérprete das ciências humanas em face à experiência da verdade ligada inextrincavelmente às suas condições históricas. Para isso, as bases de uma postura neutra e dogmática deveriam ser progressivamente abandonadas da problemática da filosofia da história, abrindo caminho a uma experiência hermenêutica que reconduza filosoficamente a consciência humana em relação à sua experiência com o mundo.

Em O problema da consciência histórica, Gadamer ressaltou a duplicidade que guarda a consciência histórica para o ser humano contemporâneo, se apresentando ao mesmo tempo como privilégio e como um fardo. Privilégio, porque a consciência histórica tem em vista a historicidade de todo presente e da relatividade de toda opinião, o que denota a desconstrução de todo dogmatismo. E fardo porque se apresenta na tarefa pesarosa de uma hermenêutica filosófica universal que se pauta em ser crítica e ressignificativa, e para isso engloba a tradição histórica como um todo, não apenas aos textos ou à tradição oral, mas a todo um complexo que os seres humanos carregam em seu presente, como expressões espirituais, gestos e comportamentos que fazem parte da experiência interpretativa. Para Gadamer, todo sentido necessita possuir uma mediação, ele parte de algum lugar e a tarefa da interpretação é ultrapassar a superficialidade do sentido, descobrir o significado mais "verdadeiro" ou mais próprio que se encontra escondido ${ }^{8}$ :

\footnotetext{
7 “A ulterior exigência de Gadamer por uma compreensão preocupada com a objetividade nas ciências espírito, deve ser contatada na elaboração de uma consciência de uma história efetual. Por história efetual (Wirkunsgsgeschichte) entende-se, desde o século 19, nas ciências literárias, o estudo das interpretações produzidas por uma época, ou a história de suas recepções. Nela se torna claro, que as obras, em determinadas épocas específicas, despertam e devem mesmo despertar diferentes interpretações. A consciência da história efetual, a ser desenvolvida, está inicialmente em consonância com a máxima de se visualizar a própria situação hermenêutica e a produtividade da distância temporal. Porém, a consciência da história efetual significa, para Gadamer, algo muito mais fundamental. Pois para ele, ela gozado status de 'princípio', do qual se pode deduzir toda a sua hermenêutica" (GRONDIN, 1999, p.190).

${ }^{8}$ Essa generalização da noção de interpretação remonta a Nietzsche. Segundo ele, todos os enunciados provenientes da razão são suscetíveis de interpretação, posto que seu sentido verdadeiro ou real nos chega sempre mascarado ou deformado por ideologias. De fato, a moderna metodologia de nossas ciências filológicas e históricas corresponde exatamente a essa concepção
} 
Compreender é operar uma mediação entre o presente e o passado, é desenvolver em si mesmo toda uma série contínua de perspectivas na qual o passado se apresenta e se dirige a nós. Nesse sentido radical e universal, a tomada de consciência histórica não é o abandono da eterna tarefa da filosofia, mas a via que nos foi dada para chegarmos à verdade sempre buscada. E vejo na relação de toda compreensão com a linguagem a maneira pela qual se revela a consciência da produtividade histórica. (GADAMER, 2003, p. 71).

Mas o ponto de efetivação dessa consciência hermenêutica consolida-se na circularidade hermenêutica que está na reabilitação da tradição e no reconhecimento dos preconceitos como condição da compreensão. Como lembrou Lawn, para Gadamer o termo tradição que é proveniente da palavra latina tradere deve ser lido como "passar a diante", transmitir algo de uma geração para a outra. Levando essa passagem de modo radical na circularidade, Gadamer pretendeu mostrar que a tradição não é um elemento que resiste à história e nem mesmo cai diante de uma razão imparcial, como alguém que não deve atrever-se a questioná-la, mas ao contrário: "[...] tudo aquilo que é transmitido está constantemente num processo de reelaboração, re-processamento e re-interpretação" (LAWN, 2010, p. 54).

Diante do círculo hermenêutico, o comportamento do intérprete com a tradição é a explicitação de sua historicidade, comportamento particular, íntimo, de pertença do sujeito histórico com o seu passado, ou melhor, a relação interpretativa é pré-conceitual. Gadamer destacou o ponto de partida do problema hermenêutico na condição do preconceito que antes era imposto um caráter restritivo pela Aufklärung 9 . Como esclareceu Palmer, o presente só pode ser entendido a partir dos preconceitos e intenções transmitidas pelo passado; assim, o passado não possui um teor contemplativo, não constitui quinquilharias amontadas em um museu, mas a tradição constitui uma atividade intensiva da compreensão:

A tradição não se coloca pois contra nós; ela é algo pelo qual nos situamos e pelo qual existimos; em grande parte é um meio tão transparente que nos é invisível - tão invisível como a água o é para o peixe (PALMER, 1969, p. 180).

Lawn acrescenta algo importante na retomada do conceito de tradição em Gadamer, em que esta é uma força vital inserida na cultura, não podendo nunca ser reduzida a crenças irracionais e à racionalidade, pois estas últimas estão inseridas na tradição e não o inverso:

Portanto, ignorar a tradição como um oposto da razão é ignorar que a razão pode, em si, ser uma característica da tradição. A ideia de transformar a tradição em objeto de investigação sugere, erroneamente, que existe um espaço conceitual e crítico a ser encontrado fora da tradição, um ponto arquimediano a partir do qual acessamos a racionalidade das atividades tradicionais. Nunca conseguimos escapar da tradição, pois sempre estamos nela (LAWN, 2010, p. 55).

nietzschiana. Com efeito, ela pressupõe que o material com que tais ciência trabalham (fontes, vestígios de uma época passada) constitui-se de tal modo que requer uma interpretação crítica. Essa pressuposição desempenha papel decisivo e fundamental paras as ciências modernas da vida histórica e social em geral (GADAMER, 2002, p. 19).

9 De acordo com Gadamer a Aufllärung ativou o preconceito contra o preconceito, ou seja, o preconceito é rebaixado a uma matiz negativa, sua principal crítica se dirigiu contra a tradição religiosa do cristianismo, portanto, contra a compreensão da Sagrada Escritura: “O termo alemão Vorurteil (preconceito) - assim, como o termo francês préjugé mas de modo ainda mais pregnante - parece ter sido restringido, pela Aufklärung e sua crítica religiosa, ao significado de ‘juízo não fundamentado’. É só a fundamentação, a garantia do método (e não o encontro com a coisa como tal), que confere ao juízo sua dignidade. Aos olhos da Aufklärung, a falta de fundamentação não deixa espaço a outros modos de validade, pois significa que o juízo não tem um fundamento na coisa em questão, que é um juízo ‘sem fundamento'. Essa é a conclusão típica do espírito racionalista. Sobre ele funda-se o descrédito dos preconceitos em geral e a pretensão do conhecimento científico de excluí-los totalmente" (GADAMER, 2015, p. 361). 
Para fundamentar seu argumento, Gadamer se apoiou na crítica do Romantismo à Aufklärung, assentado na defesa da autoridade da tradição. Autoridade anônima que, de um modo ou de outro constitui nossas ações, comportamentos, determinação de nosso ser histórico e finito. Os costumes que vivenciamos atualmente podem até ser adotados livremente, no entanto, não surgem do nada, eles são engrenagens novas, forjadas a partir de antigas engrenagens. Um professor, um mestre, um sábio ancião, não estão ligados ao sentido comum de autoridade como investidura em um poder ou posse de uma sanção punitiva:

[...] mas, sim da habilidade de levantar questões e fazer com que certos tópicos pareçam cruciais, importantes e merecedores de consideração (porque eles nos levam ao âmago daquilo que nós somos, dentro dos nossos limitados horizontes culturais) (LAWN, 2010, p. 56).

O círculo ganha vantagem quando vislumbra a condução de uma autoridade genuína que tem voz diante do jogo dialógico do passado com o presente. Reconhecer a tradição, seu alcance diante de nós é discernir, cada vez mais, por meio da tarefa hermenêutica, a marca ontológica de nosso tempo. Esse discernimento tem a ver com mover de sua condição inicial, questionar os pressupostos de autoridade da tradição, conduzindo, assim, uma reflexão tanto dentro como fora do jogo hermenêutico, pois, "a compreensão correta desse sentido de autoridade não tem nada a ver com a obediência cega a um comando. Na realidade, autoridade não tem a ver com obediência, mas com conhecimento" (GADAMER, 2015, p. 371).

A contribuição do Círculo Hermenêutico para a especificidade e autonomia das Ciências Humanas está no sentido da pré-compreensão: “[...] nas ciências humanas interpretam-se os entes a partir de um horizonte de compreensão constituído pela tradição cultural e pelas práticas sociais do intérprete [...]" (SILVA, 2013, p. 60). No entanto, os pré-conceitos devem ser colocados à prova, desfazendo sua posição original é que podem se estender sobre outros horizontes.

É assim que Gadamer, o mais influente representante da hermenêutica filosófica, esboça o processo de compreender um texto como uma série de "círculos hermenêuticos". O leitor ou o intérprete lê o texto com expectativas preconcebidas (opiniões preconcebidas ou preconceitos) e faz revisões durante o trabalho (MANTZAVINOS, 2005, p. 62).

Pode-se, inclusive, abordar a relação com a alteridade a partir do círculo, já que o intérprete se lança a partir das suas pré-concepções para compreensão do outro, permitindo-se, dessa maneira, revisar ou mesmo modificar nossa posição inicial de interpretação. Para Gadamer, o círculo não é fechado, quando se parte de si para o outro e retorna a si novamente, não se pretende realizar um lacre para as possibilidades, nossos pré-conceitos são o que perfazem nosso ser, levando cada vez a uma compreensão mais autêntica do interpretado, ao abandonarmos nossos antigos pré-conceitos significa que estamos acessíveis a novas abordagens de compreensão:

O círculo da compreensão não é cumulativo, não é um círculo fechado que se fecha sobre si mesmo, não tem a forma de uma circunferência, mas de uma espiral. Por isso, "não é correto falar em compreender melhor", como se a verdade fosse um objeto a ser alcançado ao final do processo de elaboração de compreensão e de uma vez para sempre. Não se trata de um círculo epistemológico-metodológico, que se efetiva nos padrões da relação sujeito-objeto, mas de um círculo ontológico-hermenêutico, que explicita a 
prévia estrutura da compreensão e concebe a verdade como o sentido possível de ser manifestado e jamais esgotável (ALMEIDA, 2002, p. 275-276).

Diante da circularidade hermenêutica se evidencia a postura filosófica que traça a hermenêutica de Gadamer, a qual consiste em abrir fronteiras diante do reducionismo historicista. Conhecer não implica acessar um conjunto de verdades demonstrativas, quebra-se o experimental do naturalismo para se pensar a situação experiencial-hermenêutica como copertença. Nisso, aviva-se a crítica gadameriana à Dilthey, o qual partiu do indutivismo histórico e uma neutralidade interpretativa para recompor os traços gerais que consistem uma época. Em Dilthey a consciência histórica está eminentemente ligada a evitar a relatividade para torná-la objetiva, condicionada e limitada, que encontra não no saber absoluto, mas na experiência histórica. Dilthey retomou a questão viconiana, pensando a história como aquilo que pode ser objetivamente conhecido, pois é feito pelo ser humano. A oposição de Gadamer à Dilthey já estaria, segundo Palmer, no próprio esforço da tradução da expressão alemã Wirkungsgeschichtliches Bewusstsein, que poderia ser descrito como "consciência em que a história atua constantemente" ou, mais adequadamente, "consciência histórica operativa", esta última para Palmer constitui uma forma mais adequada de se recorrer ao sentido dialéticoexperiencial do termo desvinculado da esfera da reflexividade do ser-em-si-e-para-si hegeliano.

A dialética da consciência histórica constitui a operação de uma circularidade hermenêutica tomando a distância temporal que representa a própria tensão entre o passado e o presente. Tal distância se encontra, segundo Gadamer, como mediação entre a tentativa de objetividade da tradição e a nossa própria condição de pertença à tradição. A consciência do intérprete das ciências humanas deve desvencilhar a homogeneidade da sua situação histórica na medida em que compreende. Na distância, a tarefa hermenêutica movimenta-se afastando os preconceitos prejudiciais, abrindo espaço para experienciar verdades a partir do processo dialético da conversação que faz vir a fala, o tema ou sentido de uma obra de arte, um texto, uma expressão.

\footnotetext{
Entretanto, o verdadeiro sentido contido num texto ou numa obra de arte não se esgota ao chegar a um determinado ponto final, visto ser um processo infinito. Não se eliminam apenas novas fontes de erro, de modo a filtrar todas as distorções do verdadeiro sentido. Antes, estão surgindo sempre novas fontes de compreensão, revelando relações de sentido insuspeitadas. A distância temporal que possibilita essa filtragem não tem uma dimensão fechada e concluída, mas está ela mesma em constante movimento e expansão. Ao lado do aspecto negativo da filtragem operada pela distância temporal, aparece, simultaneamente, seu aspecto positivo para a compreensão. Essa distância, além de eliminar os preconceitos de natureza particular, permite o surgimento daqueles que levam a uma compreensão correta (GADAMER, 2015, p. 395).
}

O livro, o quadro, até mesmo um ditado popular, carregam a história efeitual, levam consigo a carga conceitual de um passado que exige clarificar seu real significado, mas que, ao mesmo tempo, exige uma consciência aplicada sobre os efeitos que a história ou a tradição desempenham sobre nós. Aqui, se desenlaça a consciência da história efeitual na viva relação entre o círculo hermenêutico, a distância temporal e a fusão de horizontes. Tal relação sobrevive na distinção entre falsos preconceitos que causam mal-entendidos e os verdadeiros preconceitos pelos quais compreendemos com o ponto culminante do desenrolar de uma hermenêutica crítica. Para Gadamer, a tradição constitui um outro que nos interpela, isto sendo a condição e princípio de toda compreensão. Assim, o intérprete das ciências humanas deve, no jogo dialógico com a tradição, tomar consciência dos seus próprios preconceitos, deve provocá-los, ou seja, explicitar 
os pressupostos existenciais, colocá-los à prova e suspender sua validez, sendo receptivo para outras perspectivas.

Revela-se a hermenêutica perpassada pela estrutura da pergunta, conjuntamente com as questões da linguagem e a relação da alteridade em Gadamer, pois, a pergunta, como abertura de possibilidades face ao que diz o outro, coloca em jogo o próprio preconceito do intérprete, isto não quer dizer ser substituído imediatamente pelo outro, mas, colocar um intermédio dialógico para repensar as condições históricas da sua própria existência, refazendo, desta maneira, o modo de compreender a tradição e o próprio presente. Face a tal situação, a hermenêutica filosófica produz um movimento reflexivo na própria historicidade, pois, ao dialogar com a tradição compreende não só seu desenlace, mas, principalmente, seus efeitos no presente.

O que temos a partir do círculo hermenêutico é a relação ou encontro de horizontes distintos, o horizonte do presente com o passado, o horizonte pré-conceitual do intérprete e o horizonte da tradição. Tal relação constitui a fusão de horizontes e nela a compreensão hermenêutica desempenha e produz a linguagem que, aqui, constitui a experiência de sentido que se aviva em face do texto ou do fato estudado. Aqui, Gadamer retomou o conceito de "fusão de horizontes", também manifestando sua a crítica ao objetivismo, ao mesmo tempo, que pretendeu aferir o uso linguístico da comunicação na circularidade.

Do ponto de vista da hermenêutica filosófica gadameriana, esta mesma orientação para o conceito de horizonte é empregada, mas está intimamente ligada à concepção de consciência histórica efeitual, porque envolve a consciência da situação hermenêutica em face à tradição. Nesse ponto, impõe-se o esforço de obter o horizonte de questionamentos adequados, nos quais o intérprete tem como tarefa iluminar o sentido da tradição por meio do diálogo aberto com o texto. Mas essa relação não é unilateral, na medida em que o intérprete se move sobre o horizonte do passado e também alarga seus horizontes de possibilidades significativas, podendo tornar-se mais consciente da alteridade do outro:

O conceito de horizonte se torna aqui interessante, porque expressa essa visão superior mais ampla, que aquele que compreende deve ter. Ganhar um horizonte quer dizer sempre aprender a ver mais além do próximo e do muito próximo, não para apartá-lo da vista, senão que precisamente para vê-lo melhor, integrando-o em um todo maior e em padrões mais corretos. (GADAMER, 2015, p. 310).

Este tornar-se consciente não constitui formar um horizonte fechado no objetivismo que persiste sobre a forma de auto-alienação da metodologia moderna que converte a tradição ou o passado histórico em objeto de compreensão com verdade determinada. $O$ horizonte de compreensão é abertura interpretativa. Frente à situação da tradição, a verdade que se desvela não se esgota completamente no saber-ser. $O$ intérprete não desvencilha do seu próprio presente, traz consigo sua situação hermenêutica determinada pelos seus preconceitos, ou seja, sentimentos, opiniões, valorações, que são pontos de partida para esforçar-se na compreensão do passado histórico:

Por isso, deve ser uma tarefa constante impedir uma assimilação precipitada do passado com as próprias expectativas de sentido. Só então se chega a ouvir a tradição tal como ela pode fazer-se ouvir em seu sentido próprio e diferente". (GADAMER, 2015, p. 404).

Este horizonte pré-conceitual do intérprete não é totalmente consolidado ou definitivo, se coloca à prova e está em um processo contínuo de formação, assim, congrega-se em uma fusão de horizontes, com finalidade de ampliar suas possibilidades compreensivas, tanto do presente vivenciado pelo intérprete, como do passado ou tradição à qual ele se debruça: 
O horizonte do presente não se forma pois à margem do passado. Nem mesmo existe um horizonte do presente por si mesmo, assim como não existem horizontes históricos a serem ganhos. Antes, compreender é sempre o processo de fusão desses horizontes presumivelmente dados por si mesmos. Nós conhecemos a força dessa fusão sobretudo de tempos mais antigos e de sua relação para consigo mesmos e com suas origens. A fusão se dá constantemente na vigência da tradição, pois nela o velho e o novo crescem sempre juntos para uma validez, sem que um e outro cheguem a se destacar explicitamente por si mesmos [...] Todo o encontro com a tradição realizado com consciência histórica experimenta por si mesmo a relação de tensão entre texto e presente. A tarefa hermenêutica consiste em não ocultar esta tensão em uma assimilação ingênua, mas em desenvolvê-la conscientemente (GADAMER, 2015, p. 404-405).

A fusão de horizontes consiste na forma de realização da conversação que o intérprete mantém com o texto, em que chega a expressão de uma linguagem comum a ambos participantes do diálogo. Por conseguinte, a conversação que se estabelece nesse círculo hermenêutico de perguntas e respostas para o desenvolvimento da consciência histórica efeitual travado entre o intérprete e a tradição é o desdobramento do que Gadamer intitulou de linguisticidade da compreensão: “A relação essencial entre linguisticidade e compreensão se mostra, para começar, no fato de que a essência da tradição consiste em existir no médium da linguagem, de maneira que o objeto preferencial da interpretação é de natureza linguística". (GADAMER, 2015, p. 504).

Situar-se na linguagem é reconectar-se com a historicidade, fazendo com que a situação recíproca de diálogo e ressignificação ligue o presente ao passado. A fusão de horizontes é a vivência desse âmbito da linguisticidade da compreensão em que a tradição vem à fala no diálogo, delineando as curvas do seu verdadeiro sentido. Aqui não se expressa uma imediatez, nem se experiencia a tradição como relíquia do passado, se trata de ir para além das figuras plásticas da fixidez de sentido expostas em um museu para afirmar a relevância da transmissão de sentido hermenêutico, que se manifesta em forma de oralidade e da escrita.

Essa constante mediação do passado e do presente está na raiz da ideia gadameriana de uma "fusão de horizontes". Entender o passado não é sair do horizonte do presente, e de seus pré-juízos, para se transpor para o horizonte do passado. É, na realidade, traduzir o passado na linguagem do presente, onde se fundem os horizontes do passado e do presente. Desse modo, a fusão é tão bem-sucedida que não se consegue mais distinguir o que provém do passado em o que resulta do presente, de onde a ideia de "fusão". Mas essa fusão do presente e do passado também é, mais fundamentalmente, a do intérprete com aquilo que ele entende (GRONDIN, 2012, p. 73).

A relação entre a linguagem e a hermenêutica provoca o conhecimento de verdades e discernimentos desvelados no âmbito onto-fenomenológico da comunicação, isto implica que, como fenômeno da conversação, o ser que vem à fala não possui alguém que dirige ou dá o encaminhamento correto para o acordo; na verdade, o acordo só é possível na dialética da conversação. A retomada ao conceito da dialética, também pode significar a retomada à retórica, constituiu uma referência direta à Platão e, como esses conceitos tomam sua efetivação na plenitude do diálogo, Gadamer aproveitou nele a dialética da pergunta e da resposta como desenvolvimento dinâmico da circularidade hermenêutica: "Para Gadamer, em Platão já é possível perceber o fenômeno hermenêutico, que tem sua consumação, não na certeza metodológica sobre si mesmo, mas na abertura à experiência que distingue o homem experimentado do homem dogmático (ALMEIDA, 2002, p. 174). A pergunta é, de acordo com Gadamer, o que deve ser destacado na dialética platônica e, nesse sentido, uma referência 
importante para o fenômeno hermenêutico. A pergunta contribui e protege a própria linguagem, fazendo com que exista um movimento no diálogo permanente e provocativo, evitando a todo custo pretensos dogmatismos que residem no âmbito das respostas.

Essa é razão porque a dialética se concretiza na forma de perguntas e respostas, ou seja, todo saber acaba passando pela pergunta. Perguntar quer dizer colocar no aberto. Abertura daquilo sobre o que se pergunta consiste no fato de não possuir uma resposta fixa. Aquilo que se interroga deve permanecer em suspenso na espera da sentença que fixa e decide. $O$ sentido do perguntar consiste em colocar em aberto aquilo sobre o que se pergunta, em sua questionabilidade. Ele tem de ser colocado em suspenso de maneira que se equilibrem o pró e o contra. $O$ sentido de qualquer pergunta só se realiza na passagem por essa suspensão, onde se converte em uma pergunta aberta. (GADAMER, 2015 , p. 474).

O desenvolvimento da questão da dialética da pergunta e resposta será amadurecido na terceira parte de Verdade e método I, intitulada por Gadamer como A virada ontológica da hermenêutica no fio condutor da linguagem, em que o autor utilizou o conceito de linguisticidade (Sprachlichkeit) para fundamentar o caráter fático ou de finitude da linguagem. Nesta parte, a linguagem é descrita por Gadamer como um médium ou meio pelo qual se realiza a experiência hermenêutica. Schimidt (2014) organizou essa concepção de Gadamer em dois modos, ou seja, interpretou que a linguagem como um meio pelo qual as conversas ocorrem, mas também, como meio pelo qual se pode compreender textos. Ambos os horizontes levam a compreensão da linguagem como meio da conversação que manifesta o esforço do acordo, ambos implicam no esforço da persuasão para fazer vir o sentido do texto.

\section{Considerações finais}

Como se pode concluir a filosofia de Gadamer é a hermenêutica, isso porque a hermenêutica é crítica ou filosófica e não apenas ocasional, como o filósofo alemão costumava chamar aquelas hermenêuticas modernas que se reduziam a interpretação científica e especializada. A construção da hermenêutica filosófica gadameriana é fruto da aproximação e adoção do filósofo por algumas perspectivas não-metodológicas da hermenêutica. Esse caminho diferencial tem por objetivo reconduzir a tarefa compreensão para a ressignificação dos processos típicos das ciências humanas. Não que Gadamer esteja preocupado em lançar uma metodologia específica para servir como paradigma suficiente, o que seria, na visão do filósofo reduzir a compreensão, mas Gadamer deseja lançar uma ressignificação mais abrangente para ciências humanas, afim de que estas possam ter uma tarefa mais ativa no que denominou de consciências histórica efeitual. Consciência possível, no entender de Gadamer, a partir da imbricação lingüística se reveste no encontro dialógico da fusão de horizontes e do círculo hermenêutico. Importante lembrar que essas noções não são novidades na filosofia, pois já foram empregados pelos antecessores de Gadamer, como Dilthey e Heidegger. $O$ que existe inovador é a capacidade gadameriana de recobrar os conceitos de seus antecessores para desenvolver uma hermenêutica das ciências humanas situada no mundo da vida, na faticidade.

A hermenêutica filosófica gadameriana é a potencialização do diálogo na interpretação das ciências humanas. A sensibilidade para com o sentido turbulento do mundo requer saber que a verdade está ai, não para ser apreendida cientificamente, ao contrário, ela está no fato da experiência fática do intérprete sobre a coisa que não apenas está aí para ser descortina, mas que descortina o intérprete na medida que esse transpõe seus preconceitos para outras formas de compreender. A linguagem penetra no modo de ser do intérprete, por isso que não pode ser tomada apenas como ocasião, pois move a compreensão para o outro que convoca para o 
diálogo. Conclui-se que a hermenêutica em Gadamer é esse misto de compreensão e linguagem que conduz para uma desconstrução de um sentido unívoco do real, para nos engajarmos na pluralidade de interlocutores. 


\section{Referências}

BACON, F. O progresso do conhecimento. Trad.Raul Filker. São Paulo: Editora Unesp, 2007.

CHALMERS, A.F. O que é ciência afinal? Trad. Raul Filker. São Paulo: Editora Brasiliense, 1993.

DESCARTES, R. Discurso do método. Trad. Maria Ermania Galvão. São Paulo: Manrtins Fontes, 2011.

GADAMER, Hans-Georg. Verdade e método I. Trad. Flávio Paulo Meurer. 10.ed. Petrópolis Rio de janeiro: Editora Vozes, 2015.

GADAMER. Hans-Georg Verdade e método II: complementos e índices. Trad. Marcia Sá Cavalcante-Schuback. Petrópolis: Vozes, 2010.

GADAMER. Hans-Georg. O problema da consciência histórica. Trad. Paulo Cesár Duque Estrada. (Org. Pierre Fruchon). Rio de Janeiro: Editora FGV, 2003.

GRONDIN, Jean. Hermenêutica. Trad. Marcos Marcionilo. São Paulo: Parábola Editorial, 2012. GADAMER. Hans-Georg. Introdução à hermenêutica filosófica. Trad. Benno Dischinger. São Leopoldo: Editora UNISSINOS, 1999.

HEIDEGGER. M. Ser e Tempo. 6 ed. Petróplolis, RJ: Vozes; Bragança Paulista, SP: Editora Universitária São Francisco, 2012.

LAWN, Chris. Compreender Gadamer. Trad. Hélio Magri Filho. 2.ed. Petrópolis: Vozes, 2010.

LAWN, Cris; KEANE, Nial. The Gadamer dictionary. London: Continuum, 2011.

LÉVINAS. Descobrindo a Existência com Husserl e Heidegger. 2. ed. Lisboa: Ed. Instituto Piaget, 1967.

MANTZAVINOS, Chrysostomos. O círculo hermenêutico: que problema é este? Tempo Social Revista de Sociologia da USP. V. 26, n. 2 2005, p 57-69.

MILL, John Stuart. A Lógica das ciências morais. Trad. de Alexandre Braga Massella. São Paulo: Iluminuras, 1999.

NIETZSCHE, Friedrich. A vontade de poder. Trad. Marcos Sinésio Pereira Fernandes. Rio de Janeiro: Contraponto, 2011.

NUNES, Benedito. Passagem para o poético: filosofia e poesia em Heidegger. 2. ed. São Paulo: Editora Ática, 1992.

PALMER. Richard. Hermenêutica. Trad. Maria Luísa Ribeiro Ferreira. Lisboa: Edições 70, 1969.

SCHMIDT. Lawrence K. Hermenêutica. 3. ed. Trad. Fábio Ribeiro. Petrópolis, RJ: Vozes, 2014. SILVA, Rui Sampaio. O círculo hermenêutico e a distinção entre ciências humanas e ciências naturais. Ekstases: revista de fenomenologia e hermenêutica. Rio de Janeiro, v.1 n.2, 2013, p. 5472.

WEINSHEIMER, Joel C. Gadamer's hermeneutics: a Reading of truth and method. New York: Yale University Press. 1985.

Autor(a) para correspondência: Paulo Thiago Alves Sousa, Av. Nossa Sra. de Fátima - Bairro Reis Veloso, 64202220, Parnaíba - PI, Brasil.pthiago21@hotmail.com 